\title{
A case report of rare location of ganglioglioma
}

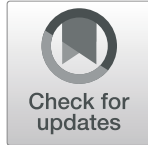

Vikas Sharma ${ }^{*}\left(\mathbb{D}\right.$, S. Bhaskar², Sumit Ramdas Hire ${ }^{2}$ and Arvind Ahuja ${ }^{3}$

\begin{abstract}
Background: Gangliogliomas are rare tumors of the central nervous system. They can occur anywhere in the central nervous system but are most commonly located in the temporal lobe and are mainly found in children. Anaplastic ganglioglioma can result from either de novo or transformation of a pre-existing lesion.

Case presentation: We report a case of de novo anaplastic ganglioglioma in the parieto occipital region, which is a rare location. A 34-year-old lady presented with features of raised intracranial pressure (ICP) with right side hemiparesis. Contrast-enhanced magnetic resonance imaging (CEMRI) of the brain showed welldefined intense heterogenously enhancing solid cystic mass lesion $5.3 \times 5.2 \mathrm{~cm}$ in the left parieto occipital region with mass effect and midline shift. Intraoperatively, a cystic mass lesion with reddish brown nodule was seen in the left occipital lobe. Complete tumor excision was done. Microscopic and IHC examination was suggestive of anaplastic ganglioglioma. The post-operative period was uneventful. The patient received $60-G y$ radiotherapy with temozolamide as adjuvant therapy, and repeat imaging showed no tumor recurrence.
\end{abstract}

Conclusion: Anaplastic gangliogliomas are rare tumors with parieto occipital as rare location.

Keywords: Ganglioglioma, Tumor, Children, Radiotherapy

\section{Background}

Gangliogliomas are rare tumors, and they account for $1 \%$ (reported range of 0.4 to $7 \%$ ) of all central nervous system neoplasms [1]. They are commonly seen in children and young adults with males affected more commonly than females [1]. These tumors occur throughout the CNS, but the temporal lobe is the commonest site [2]. The most common presentation is seizures. They are generally of WHO grades 1 and 2, and grade 3 (anaplastic ganglioglioma) is very rare. In $5 \%$ of cases, gangliogliomas show aggressive behavior and anaplastic histopathologic features characteristic of $\mathrm{WHO}$ grade 3 tumors [3]. These tumors can occur de novo or as a result of malignant transformation of a pre-existing lesion. We report here a rare case of de novo occipital anaplastic ganglioglioma. On searching the English literature, a total of 41 cases of de novo anaplastic ganglioglioma have been reported with only 4 cases in parieto occipital location.

\footnotetext{
* Correspondence: vikassurg2015@gmail.com

${ }^{1}$ Department of Neurosurgery, Bombay Hospital, Marine lines, Mumbai, India Full list of author information is available at the end of the article
}

The details of the previously reported cases have been summarized in Table 1.

\section{Case presentation}

A 34-year-old female presented with complaints of on/off headache with vomiting for 1 year, which aggrevated for the last 5 days. Systemic examination was within normal limits. GCS was E4V5M6, pupils were bilateral normal size and reacting, on fundus examination-bilateral papilledema was present. On the motor system examination, right side hemiparesis was present (motor power 4/5). Contrast-enhanced magnetic resonance imaging (CEMRI) of the brain showed well-defined intense heterogenously enhancing solid cystic mass lesion $5.3 \times 5.2 \mathrm{~cm}$ in the left parieto occipital region. Solid component was isointense on T2/ FLAIR images with peripheral cystic areas and isointense on T1W images. The cystic component was isoto hyperintense on T2/FLAIR images and hypointense on T1W images. The lesion showed mass effect in form of compression and displacement of the occipital horn of the lateral ventricle and compression of 
Table 1 Previously published cases

\begin{tabular}{|c|c|c|c|c|c|c|c|}
\hline S no & Authors/year & Age/sex & Location & Resection & Follow-up & RT & $\mathrm{CT}$ \\
\hline 1 & Hall et al. 1986 [4] & 6 months/F & Right frontal & Not mentioned & 20 months & No & - \\
\hline 2 & Lang et al. [4] & - & - & - & - & - & - \\
\hline 3 & Hirose et al. 1992 [5] & 12 years/F & Brain stem & Not mentioned & Not mentioned & Yes & Yes \\
\hline 5 & Wolf et al. 1994 [6] & - & - & - & - & - & - \\
\hline 6 & & - & - & - & - & - & - \\
\hline 7 & Prayson et al. 1995 [4] & - & - & - & - & - & - \\
\hline 8 & Campos et al. 1994 [4] & 10 years/M & Left temporal & - & 6 months & - & - \\
\hline 9 & Hakim et al. 1997 [4] & 47 years $/ M$ & Frontal & Total & 14 months & SRS & Yes \\
\hline 10 & Nakajima et al. 1998 [4] & 7 years/F & Right parieto occipital region & Subtotal & 15 months & Yes & Yes \\
\hline 11 & Araki et al. 1999 [4] & 53 years $/ F$ & Frontal & Total & 26 months & Yes & Yes \\
\hline 12 & Danjoux et al. 2001 [4] & 26 years/M & Temporal & - & 2 months & Yes & - \\
\hline 13 & Suzuki et al. 2002 [4] & 59 years/M & Temporal & - & - & - & - \\
\hline 14 & Nair et al. 2004 [4] & 60 years/M & Right parietal & - & - & - & - \\
\hline 15 & Lyken et al. 2004 [4] & - & - & - & 11 years & Yes & Yes \\
\hline 16 & & - & - & - & - & Yes & Yes \\
\hline 17 & Kang et al. 2007 [4] & 45 years $/ M$ & Left frontal & Subtotal resection & 35 months & Yes & Yes \\
\hline 18 & Majores et al. 2008 [7] & 45 years $/ M$ & Left temporo mesial & Total & 11 months & Yes & Yes \\
\hline 19 & & M & - & - & - & Yes & Yes \\
\hline 20 & & M & - & - & - & Yes & Yes \\
\hline 21 & & M & - & - & - & Yes & Yes \\
\hline 22 & & $\mathrm{~F}$ & - & - & - & Yes & Yes \\
\hline 23 & Karremann et al. 2009 [4] & 2 years/M & Left fronto basal & Total & 31 months & No & No \\
\hline 24 & & 3 years/M & Right frontal & Total & 54 months & No & Yes \\
\hline 25 & & 10 years/F & Right frontotemporoparietal & Total & 42 months & Yes & Yes \\
\hline 26 & & 10 years/M & Right parieto occipital & Partial & 6 months & Yes & Yes \\
\hline 27 & & 14 years/M & Pons and fourth ventricle & Subtotal & 8 months & Yes & No \\
\hline 28 & & 16 years $/ F$ & Right temporo mesial & Total & 25 months & Yes & No \\
\hline 29 & Kawataki et al. 2010 [4] & 34 years/M & Left medial temporal & Subtotal & 6 months & Yes & Yes \\
\hline 30 & A.E. Rojas et al. 2013 [8] & 22 years/M & Left frontotemporal lobes & - & 11 months & Yes & - \\
\hline 31 & & 24 years/F & Left frontotemporal lobes & - & 3 months & Yes & - \\
\hline 32 & & 25 years $/ M$ & Left frontotemporal lobes & - & 6 months & Yes & - \\
\hline 33 & & 34 years/M & Left frontal & - & 9 months & Yes & - \\
\hline 34 & & 9 years/M & Posterior fossa & - & 6 months & Yes & - \\
\hline 35 & & 9 years/M & B/L basal ganglia & - & 2 months & Yes & Yes \\
\hline 36 & & 37 years $/ M$ & Left frontotemporal region & - & 2 months & Yes & - \\
\hline 37 & Lucas et al. 2015 [9] & 12 years/M & Left temporoparietal & Subtotal & 23 months & Yes & Yes \\
\hline 38 & & 11 years/M & Right temporal & Subtotal & 22 months & Yes & Yes \\
\hline 39 & Pikis et al. 2017 [10] & 34 years/F & Left frontal & Subtotal & 12 months & Yes & Yes \\
\hline 40 & Lundar et al. 2018 [11] & 15 years/M & Supratentorial & Total & 14 years & - & - \\
\hline 41 & & 19 years/M & Supratentorial & Total & 12 months & - & - \\
\hline 42 & Present study & 34 years/F & Left parieto occipital & Total & 26 months & Yes & Yes \\
\hline
\end{tabular}

the brain stem with midline shift and brain edema. These features were suggestive of hemangioblastoma/ pilocytic astrocytoma (Fig. 1).
Left parieto occipital craniotomy was done which showed a cystic mass lesion with reddish brown solid nodule in the occipital region. Cyst was tapped followed 

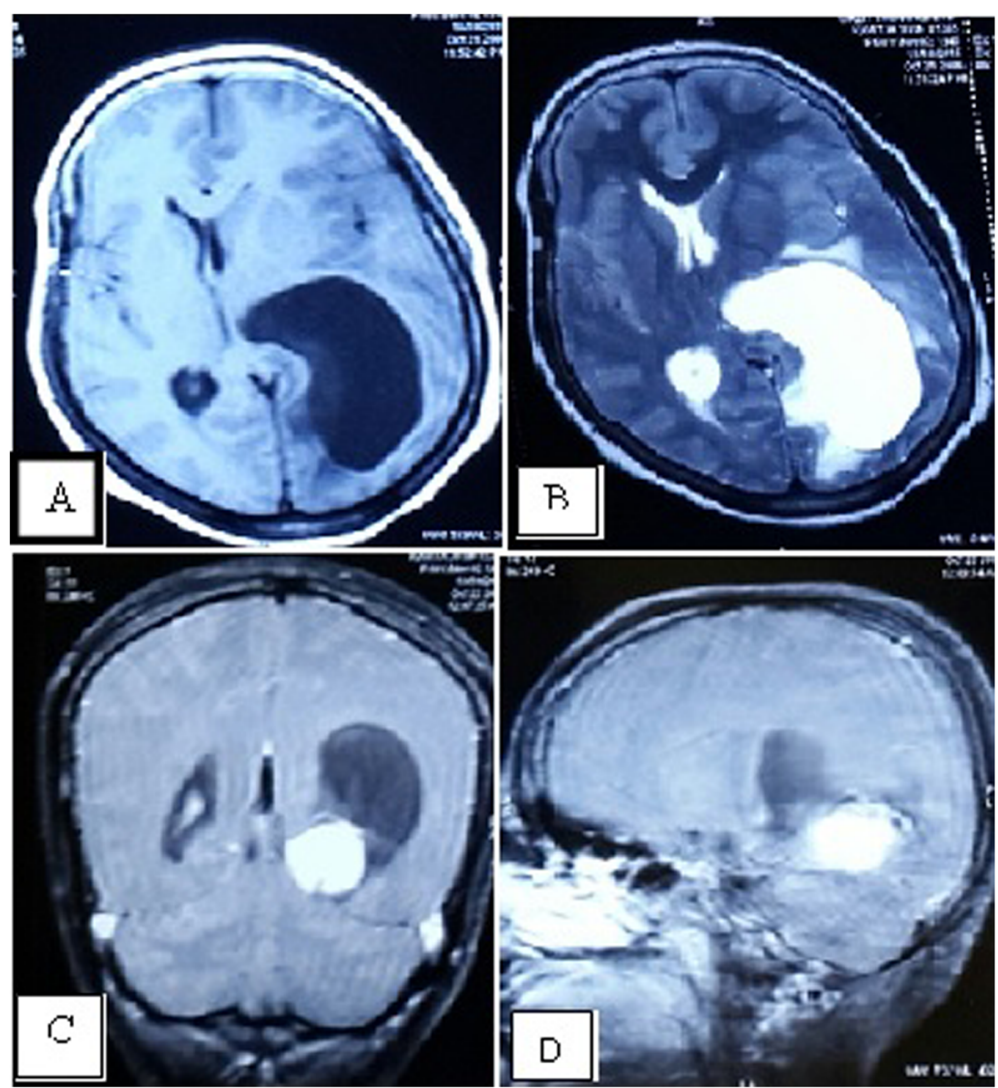

Fig. 1 CEMRI of the brain shows a well-defined solid cystic lesion in the left parieto occipital region. Solid component isointense and cystic component hypointense on T1 axial images (a). Solid component isointense and cystic component iso- to hyperintense on T2 axial images. Solid component shows intense enhancement on T1 contrast coronal and sagittal images (c, d), Solid component isointense and cystic component iso- to hyperintense on T2 axial images (b)

by nodule excision. The nodule was soft to firm in consistency and was mild to moderately vascular. Tumor was extending into the occipital horn and midline up to the falx; however, no attachment to the falx was seen gross total tumor excision was done.

\section{Histopathology}

Microscopic examination showed cellular glial tumor composed of malignant astrocytic cells and scattered ganglion cells. Astrocytic cells showed moderate nuclear pleomorphism with coarse chromatin with few mitosis. Immunohistochemistry (IHC) analysis showed focal positivity (ganglion cells) for CD56 and was negative for CD34, P53, IDH1, and synaptophysin. MIB1 index was $8 \%$ (Figs. 2 and 3). These features were suggestive of anaplastic ganglioglioma, WHO grade 3.

The immediate post-operative period was uneventful. The patient made gradual recovery over the and received 60-Gy radiotherapy with temozolamide as adjuvant therapy. Post-operative CEMRI of the brain showed craniotomy defect with gliosis in the left parieto occipital region with no contrast enhancement
(Fig. 4). CEMRI of the brain was done 14 and 24 months after surgery which showed post radiotherapy changes with gliosis with no recurrent lesion (Fig. 5). The patient is asymptomatic 26 months after surgery.

\section{Discussion}

Ganglioglioma is an infrequent tumor of the central nervous system, initially characterized by Perkins in 1926. The age of presentation of these tumors varies from 2 months to 70 years. The majority of gangliogliomas occur in the temporal lobe $(>70 \%)$ [7]. The most common presenting signs and symptoms are seizures (temporal lobe and other supratentorial locations), followed by headache, dizziness, ataxia (posterior fossa), and progressive weakness (spinal cord). The typical of ganglioglioma is a benign, calcified tumor in the temporal lobe of a child with seizures [3]. On CT, the picture is of a circumscribed solid mass or cyst with a mural nodule. On MR imaging, gangliogliomas are isointense to hypointense on T1weighted images, are hyperintense and heterogeneous on T2-weighted images, and can contain solid, cystic, 


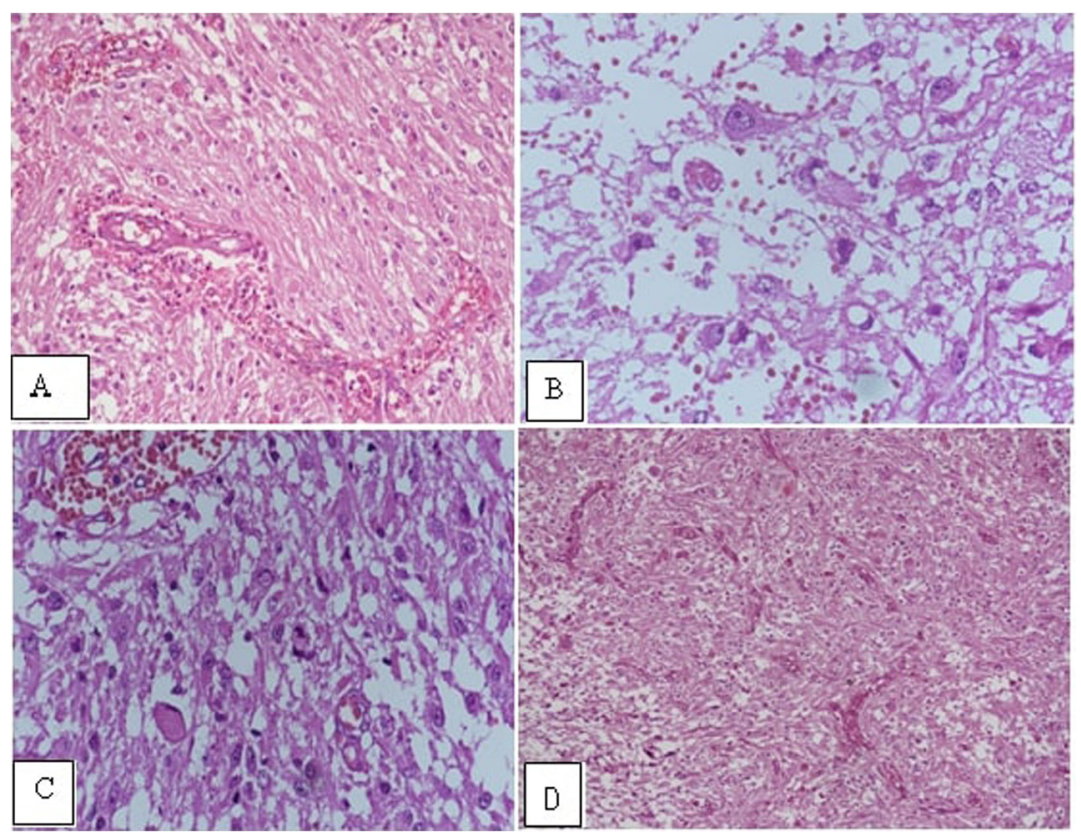

Fig. 2 Photomicrograph showing a branching capillaries and eosinophilic granular bodies seen in a fibrillary glial background. H\&E, $\times 100$. b Ganglion cells with vesicular chromatin, prominent nucleoli, and moderate to abundant amount of eosinophilic cytoplasm. H\&E, $\times 400$. c Photomicrograph showing a mitotic figure. H\&E, $\times 100$. d Cellular glial tumor composed of malignant astrocytic cells with scattered

ganglion cells and marked vascular proliferation. $\mathrm{H} \& \mathrm{E}, \times 100$

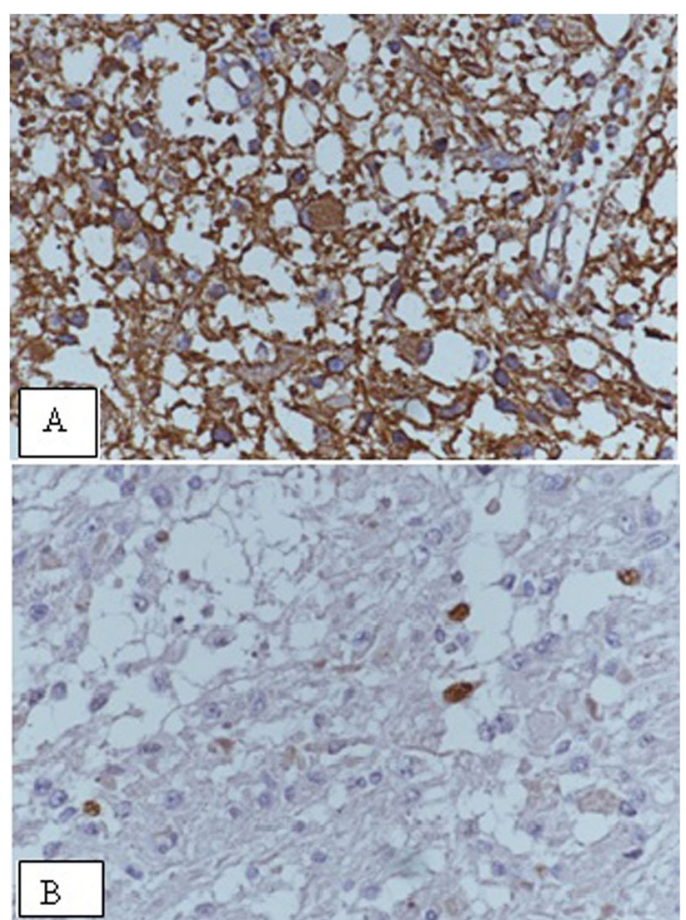

Fig. $3 \mathrm{HC}$ a ganglion cells showing cytoplasmic positivity for CD 56. b Ki67/MIB1 positivity and calcified components. Enhancement after administration of gadolinium has also been found to vary from no enhancement to marked, heterogeneous enhancement $[2,12]$.

Histopathologically, gangliogliomas are benign, welldifferentiated neuroepithelial tumors. The typical feature is a combination of neuronal and glial cell elements, which may exhibit marked heterogeneity [13]. On IHC, the glial component is positive for GFAP, S-100 protein, and vimentin, whereas the neuronal component is reactive for synaptophysin, MAP 2, NeuN, and neurofilaments [14, 15]. Histopathologic differential diagnoses comprise both high-grade and low-grade neoplasms, such as diffuse astrocytomas, oligodendrogliomas, dysembryoplastic neuroepithelial tumors, pilocytic astrocytomas (PAs), and pleomorphic xanthoastrocytomas (PXAs) [7]. Mitotic figures in ganglioglioma are rare, and MIB index varies from 1.1 to $2.7 \%$. CD 34 is present $70-80 \%$ in the neuronal component of ganglioglioma but is less common in anaplastic variants [15]. IDH1 and P53 should be done to rule out diffuse glioma.

Anaplastic gangliogliomas typically demonstrate malignant transformation of the glial component with hypercellularity, vascular proliferation, and necrosis high mitotic labeling indices (Ki-67) [16-18]. Anaplastic transformation is more common in the pediatric population and has been associated with previous 


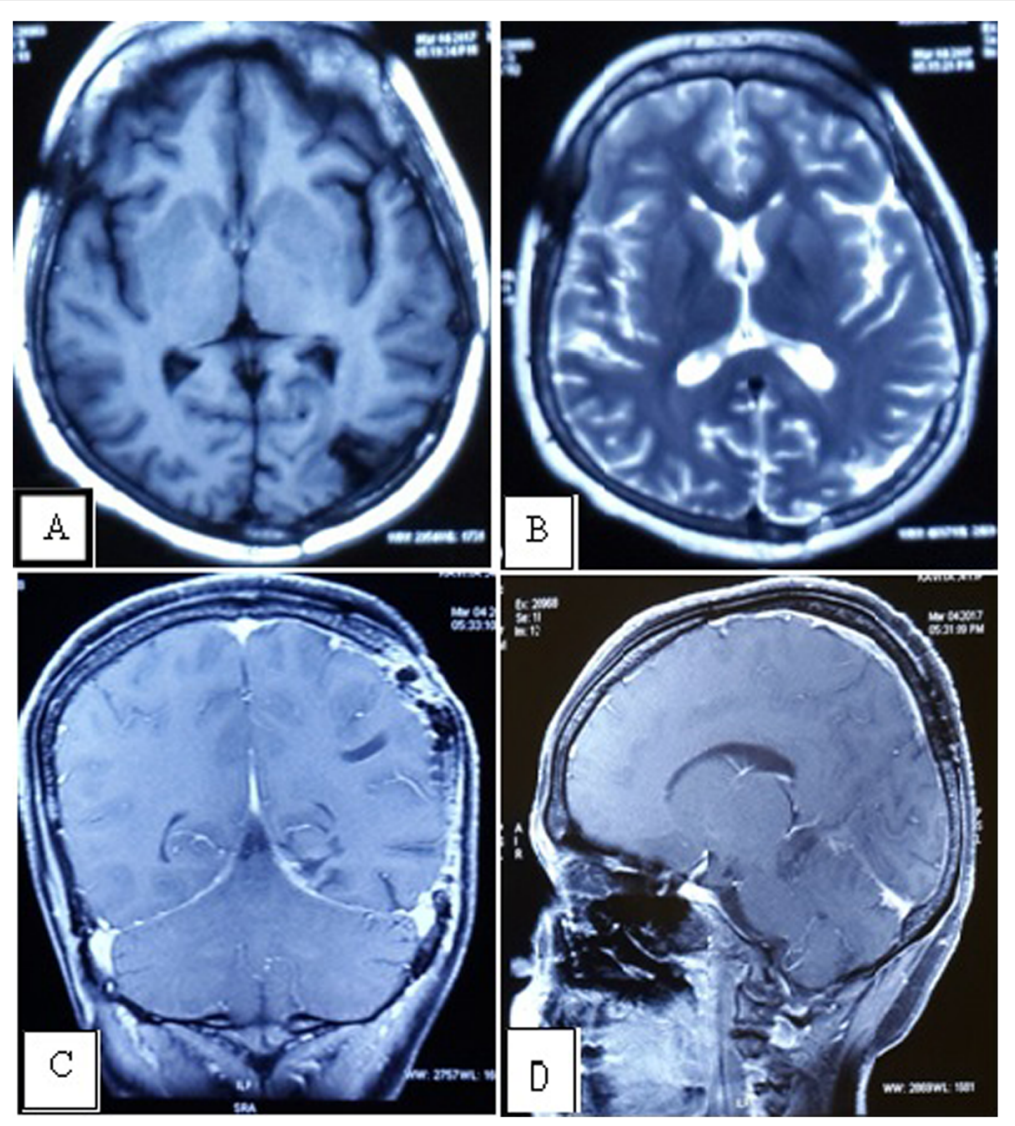

Fig. 4 Post-op CEMRI of the brain shows post-operative changes with no contrast enhancement. $T 1$ and $T 2$ axial $(\mathbf{a}, \mathbf{b})$ and $T 1$ with contrast coronal and sagittal $(\mathbf{c}, \mathbf{d})$

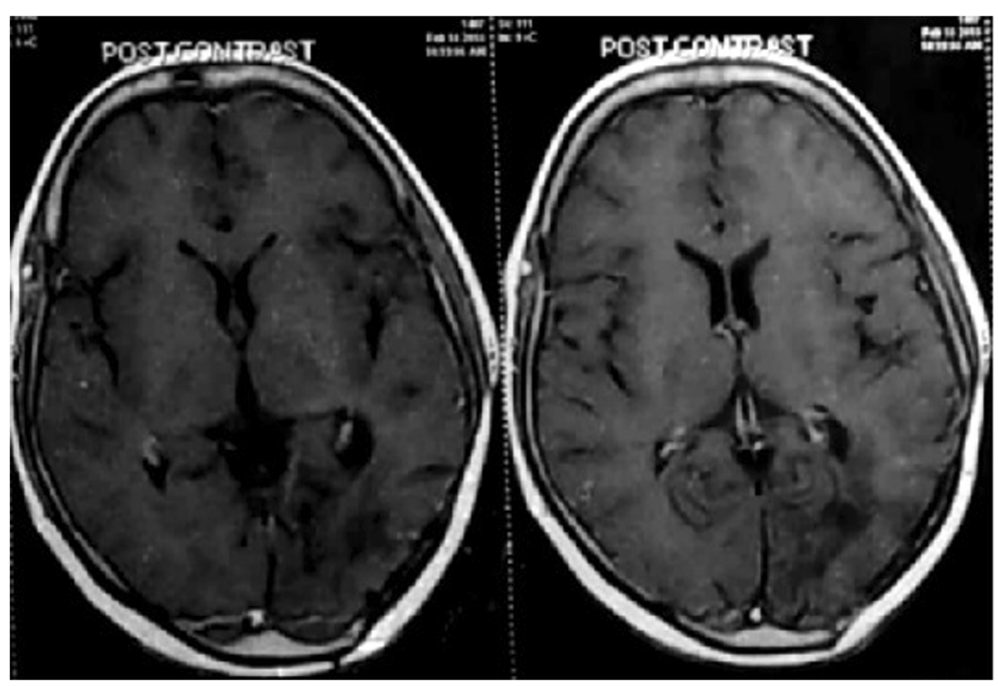

Fig. 5 CEMRI brain T1 contrast image done after 14 months of surgery showing post radiotherapy changes with no enhancement 
subtotal tumor resection and radiotherapy [19]. Gross total resection should be attempted whenever possible with the preservation of neurological function. Some studies have advocated the role of gross total resection along with adjuvant radiochemotherapy in achieving good survival rates [20,21].

\section{Conclusion}

Anaplastic gangliogliomas are rare tumors with parieto occipital as rare location. Imaging may vary, and histology along with IHC is needed for the diagnosis. Gross total resection along with adjuvant therapy improves outcome.

\section{Abbreviations}

CEMRI: Contrast-enhanced magnetic resonance imaging; ICP: Intracranial pressure; IHC: Immunohistochemistry; PAs: Pilocytic astrocytomas; PXAs: Pleomorphic xanthoastrocytomas

\section{Acknowledgements}

Not applicable.

\section{Authors' contributions}

VS and SB contributed to the data collection and writing of the manuscript $\mathrm{AH}$ contributed to the histopathology and $\mathrm{IHC}$ analysis part. VS and $\mathrm{SRH}$ contributed to the cross-checking and editing of the manuscript. All authors read and approved the final manuscript.

\section{Funding}

There is no external funding for the publication of this article.

\section{Availability of data and materials}

Please contact Dr. Vikas Sharma for data requests. All identifiable data (name of patients, birthdate) have been removed out of the figure scans.

\section{Ethics approval and consent to participate}

As this is a case report, ethical clearance is not required.

\section{Consent for publication}

Consent for publication was taken from the patient prior to reporting of the case.

\section{Competing interests}

The authors declare that they have no competing interests.

\section{Author details}

${ }^{1}$ Department of Neurosurgery, Bombay Hospital, Marine lines, Mumbai, India. 2Department of Neurosurgery, PGIMER \& Dr RML Hospital, New Delhi, India.

${ }^{3}$ Department of Pathology, PGIMER \& Dr RML Hospital, New Delhi, India.

Received: 7 May 2019 Accepted: 16 October 2019

Published online: 13 November 2019

\section{References}

1. Zhang D, Henning TD, Zou LG, Hu LB, Wen L, Feng XY, Dai SH, Wang WX, Sun QR, Zhang ZG. Intracranial ganglioglioma: clinicopathological and MR findings in 16 patients. Clin Radiol. 2008;63(1):80-91.

2. Zentner J, Wolf HK, Ostertun B, Hufnagel A, Campos MG, Solymosi L, Schramm J. Gangliogliomas: clinical, radiological, and histopathological findings in 51 patients. J Neurol Neurosurg Psychiatry. 1994;57(12):1497-502.

3. Rumana CS, Valadka AB. Radiation therapy and malignant degeneration of benign supratentorial gangliogliomas. Neurosurgery. 1998;42:1038-43.

4. Demarchi R, Abu-Abed S, Munoz D, Loch Macdonald R. Malignant ganglioglioma: case report and review of literature. J Neurooncol. 2011;101: 311-8.
5. Hirose T, Kannuki S, Nishida K, Matsumoto K, Sano T, Hizawa K. Anaplastic ganglioglioma of the brain stem demonstrating active neurosecretory features of neoplastic neuronal cells. Acta Neuropathol. 1992;83:365-70.

6. Wolf HK, Muller MB, Spanle M, Zentner J, Schramm J, Wiestler OD. Ganglioglioma: a detailed histopathological and immunohistochemical analysis of 61 cases. Acta Neuropathol. 1994;88:166-73.

7. Majores M, von Lehe M, Fassunke J, Schramm J, Becker AJ, Simon M. Tumor recurrence and malignant progression of gangliogliomas. Cancer. 2008;113: 3355-63.

8. Romero-Rojas AE, Diaz-Perez JA, Chinchilla-Olaya SI, Amaro D, LozanoCastillo A, Ligia I. Restrepo-Escobar histopathological and immunohistochemical profile in anaplastic gangliogliomas. neurocirugia. 2013:24:237-43.

9. Lucas JT Jr, Huang AJ, Mott RT, Lesser GJ, Tatter SB, Chan MD. Anaplastic ganglioglioma: a report of three cases and review of the literature. J Neurooncol. 2015;123:171-7.

10. Pikis S, Petrosyan T, Diamantopoulou K, Kelesis C. Anaplastic ganglioglioma becoming symptomatic in the third trimester of pregnancy. Int J Reprod Contracept Obstet Gynecol. 2017;6:1158-60.

11. Lundar T, Due-Tønnessen BJ, Fric R, Egge A, Krossnes B, Due-Tønnessen P, Stensvold E, Brandal P. Acta Neurochir (Wien). 2018;160(6):1207-14.

12. Johannsson JH, Rekate HL, Roessmann U. Gangliogliomas: pathological and clinical correlation. J Neurosurg. 1981;54:58-63.

13. Hirose T, Scheithauer BW, Lopes MB, et al. Ganglioglioma: an ultrastructural and immunohistochemical study. Cancer. 1997;79:989-1003.

14. Blumcke I, Giencke K, Wardelmann E, Beyenburg S, Kral T, Sarioglu N, Pietsch T, Wolf HK, Schramm J, Elger CE, Wiestler OD. The CD34 epitope is expressed in neoplastic and malformative lesions associated with chronic, focal epilepsies. Acta Neuropathol (Berl). 1999;1997:481-90.

15. Blumcke I, Muller S, Buslei R, Riederer BM, Wiestler OD. Microtubuleassociated protein-2 immunoreactivity: a useful tool in the differential diagnosis of low-grade neuroepithelial tumors. Acta Neuropathol. 2004;108: 89-96.

16. Kawataki T, Sato E, Sato T, Kinouchi H. Anaplastic ganglioglioma with malignant features in both neuronal and glial components-case report. Neurol Med Chir. 2010;50:228-31.

17. Karabekir HS, Balci C, Tokyol C. Primary spinal anaplastic ganglioglioma. Pediatr Neurosurg. 2006;42:374-8.

18. Nakajima M, Kidooka M, Nakasu S. Anaplastic ganglioglioma with dissemination to the spinal cord: a case report. Surg Neurol. 1998;49:445-8.

19. Selvanathan SK, Hammouche S, Salminen HJ, Jenkinson MD. Outcome and prognostic features in anaplastic ganglioglioma: analysis of cases from the SEER database. J Neurooncol. 2001;105:539-45.

20. Karremann M, Pietsch T, Janssen G, Kramm CM, Wolff JE. Anaplastic ganglioglioma in children. J Neurooncol. 2009;92:157-63.

21. Terrier, L. M., Bauchet, L., Rigau, V., Amelot, A., Zouaoui, S., Filipiak, I., ... Club de Neuro-Oncologie of the Société Française de Neurochirurgie. Natural course and prognosis of anaplastic gangliogliomas: a multicenter retrospective study of 43 cases from the French Brain Tumor Database. Neuro-Oncol,19(5): 678-688.,2016

\section{Publisher's Note}

Springer Nature remains neutral with regard to jurisdictional claims in published maps and institutional affiliations. 